\title{
Seasonal spatial ecology of mountain lions (Puma concolor) in the central Sierra Nevada
}

\author{
Justin A. Dellinger ${ }^{1, *}$, Eric R. LofT $2, \dagger$, Ronald C. Bertram $2, \dagger$, \\ Donald L. Neal ${ }^{3, \dagger}$, Marc W. Kenyon ${ }^{1}$, and Steven G. Torres ${ }^{1}$ \\ ${ }^{1}$ Wildlife Investigations Lab, California Department of Fish and Wildlife, 1701 Nimbus Rd., Rancho Cordova, CA 95670 \\ ${ }^{2}$ Wildlife Branch, California Department of Fish and Wildlife, 1416 Ninth St., Sacramento, CA 95814 \\ ${ }^{3}$ United States Forest Service, Pacific Southwest Research Station, 2081 E. Sierra Ave., Fresno, CA 93710
}

\begin{abstract}
Mountain lions (Puma concolor) were captured and radio-collared in the Sierra National Forest between 1983 and 1992 to study the species' seasonal spatial patterns in a location where migratory mule deer (Odocoileus hemionus) are its primary prey. Some mountain lions displayed seasonal migratory shifts in elevation that mirrored those of their migratory prey; others resided at lower elevations year-round. Home range size for all mountain lions was larger in summer $\left(\bar{x}=231 \mathrm{~km}^{2}\right)$ than in winter $\left(\bar{x}=110 \mathrm{~km}^{2}\right)$, whether or not an individual exhibited seasonal migratory shifts in elevation. Due to seasonal shifts in home range size and, for part of the mountain lion population, in elevation, minimum density of mountain lions in the study area also differed seasonally (summer, 0.87 per $100 \mathrm{~km}^{2}$; winter, 1.42 per $100 \mathrm{~km}^{2}$ ). Overall, these findings demonstrate differing space use strategies (migratory vs. resident) within a large carnivore population that have important management implications for large carnivores because these strategies provide context for population monitoring and conflict mitigation efforts.
\end{abstract}

RESUMEN.-Se capturaron pumas (Puma concolor) y se les colocó collares con radares en el Bosque Nacional Sierra (Sierra National Forest) entre 1983 y 1992 para estudiar los patrones espacio-estacionales en los que el ciervo Odocoileus hemionus es su presa principal. Algunos pumas mostraron cambios migratorios estacionales en la elevación, estos reflejaban los cambios de sus presas migratorias, otros permanecieron en menores elevaciones durante todo el año. El tamaño del rango hogareño de los pumas fue mayor durante el verano $\left(\bar{x}=231 \mathrm{~km}^{2}\right)$ comparado con el invierno $(\bar{x}=$ $110 \mathrm{~km}^{2}$ ), sin importar si un individuo mostró cambios migratorios estacionales en la elevación. Debido a los cambios estacionales en la elevación en algunas poblaciones de pumas y a los cambios estacionales en el tamaño del rango hogareño, la densidad mínima de los pumas en el área de estudio también fue variable estacionalmente (verano, 0.87/100 km²; invierno, 1.42/100 $\mathrm{km}^{2}$ ). En general, estos resultados demuestran diferentes estrategias de uso del espacio (migratorias vs. residentes) en una población de grandes carnívoros, que pueden tener implicaciones importantes para su gestión, al proporcionar un contexto para el monitoreo de las poblaciones, así como los esfuerzos para mitigar conflictos.

The mountain lion (Puma concolor) is one of the most widespread yet difficult-to-study wildlife species in the Western Hemisphere (Currier 1983). Given its widespread distribution, the mountain lion is highly adaptable and can inhabit most environments from sea level to over $4500 \mathrm{~m}$ that support adequate prey (Hansen 1992, Logan and Sweanor 2001). Mountain lion populations are known to exist in low-lying swamps and wetlands (Cox et al. 2006), arid deserts (Logan and Sweanor 2001), high-elevation coniferous forests (Cooley et al. 2009), and equatorial rainforests (Kelly et al. 2008). Due to this highly adaptable nature, mountain lions potentially exhibit varying patterns of space use and life history strategies to meet daily metabolic and reproductive demands (Hornocker and Negri 2010). Thus, in order to effectively manage and conserve mountain lions, it is important to understand the ecology of local populations.

Mountain lion ecology, particularly space use, has been intensively investigated in a variety of environmental conditions across the western United States (Hornocker and Negri 2010). However, in California, mountain lion research has mostly focused on mountain lion ecology in singular environments,

*Corresponding author: justin.dellinger@wildlife.ca.gov

$\dagger$ Retired 
namely isolated or human-altered habitats. More specifically, mountain lion research in California has primarily focused on habitat connectivity (Beier 1993, Thorne et al. 2006, Morrison and Boyce 2009, Burdett et al. 2010), population viability and genetic diversity (Smallwood 1997, Ernest et al. 2003, 2014), and behavior in reference to human activity (Dickson and Beier 2002, Orlando 2008, Wilmers et al. 2013). Research done outside of this primary scope has largely focused on impacts of mountain lions on endangered prey (Wehausen 1996, Hayes et al. 2000, Pierce et al. 2000). Little work has been done on drivers of habitat use and variability in life history strategies of mountain lions inhabiting contiguous, more natural habitats in California. Pierce et al. (1999) provided a description of seasonal patterns of home range distribution of mountain lions in the eastern Sierra Nevada of California. Mountain lions were shown to have seasonal variability in home range locality, with animals exhibiting either stable annual home ranges, partially distinct seasonal home ranges, or wholly separate seasonal home ranges (Pierce et al. 1999). However, relatively little work has been done to quantitatively assess space use of mountain lions in these more remote areas of California.

Herein we perform a retrospective quantitative analysis of mountain lion spatial ecology on a 10-year data set collected from 1983 to 1992 on the western slopes of the central Sierra Nevada. We attempt to assess varying life history strategies of mountain lions and resulting impacts of such variation on space use and density. Mountain lions in this area rely primarily ( $>60 \%$ of their diet) on a combination of resident and migratory mule deer (Odocoileus hemionus), though migratory deer make up the large majority of the ungulate prey base for mountain lions in this area (Bertram and Rempel 1977, Bertram 1984, Neal et al. 1987). We hypothesize that individual mountain lions vary in their life history strategies (i.e., resident vs. migratory), reflecting the variation in life history strategies of their primary prey. As a consequence of this potential variation in life history strategies, we hypothesize that (1) at least some mountain lions exhibit seasonal migratory behaviors, (2) home range size varies seasonally, with animals having smaller home ranges in winter than in summer, (3) home range overlap varies seasonally, with higher home range overlap in winter than in summer, and (4) mountain lion density varies seasonally with higher mountain lion densities in winter than in summer. All of these hypotheses are centered on the idea that mountain lion spatial ecology reflects spatial ecology of primary prey in the Sierra National Forest (Bertram and Rempel 1977, Pierce et al. 1999, Cooley et al. 2009). For example, in this study area, it is known that a majority of mule deer herds migrate to higher elevations in summer, and all herds tend to occupy small, confined, low-elevation areas in winter (Longhurst et al. 1952, Bertram and Rempel 1977, Bertram 1984, Neal et al. 1987, Higley 2002). Given the large amount of intact public land in California, and that mountain lions are estimated to occupy at least 63 million acres of a variety of habitat types within the state (Torres et al. 1996), in-depth investigation of mountain lion spatial ecology in more contiguous, natural habitats can potentially provide wildlife managers with information to manage a large proportion of the mountain lions in California.

\section{Methods \\ Study Area}

This study was conducted in and adjacent to the Sierra National Forest in eastern Fresno County, California $\left(37^{\circ} 04^{\prime} \mathrm{N}, 119^{\circ} 11^{\prime} \mathrm{W}\right.$; Fig. 1), from August 1983 to April 1992. The Sierra National Forest was one of the premier mule deer hunting areas in the mid-1900s (Winter et al. 1970). This mountain lion study was part of a much larger study designed to quantify the population dynamics of mule deer in response to a drastic decline in deer abundance (Bertram and Rempel 1977, Bertram 1984, Neal et al. 1987). The mule deer population in this area was estimated at 17,000 in 1950 and had declined nearly $80 \%$ to an estimated 3500 animals by 1972 (Bertram and Rempel 1977, Chapel and Rempel 1981).

The study area encompassed approximately $2070 \mathrm{~km}^{2}$, ranging in elevation from 200 to $3300 \mathrm{~m}$. Climate varied seasonally, with mean daily temperatures averaging $30{ }^{\circ} \mathrm{C}$ in summer and $0{ }^{\circ} \mathrm{C}$ in winter. Mean annual precipitation averaged $125 \mathrm{~cm}$, most of which occurred between November and April. Precipitation below $1000 \mathrm{~m}$ was predominantly rainfall. Winter snowpack averaged $90 \mathrm{~cm}$ at higher elevations. 


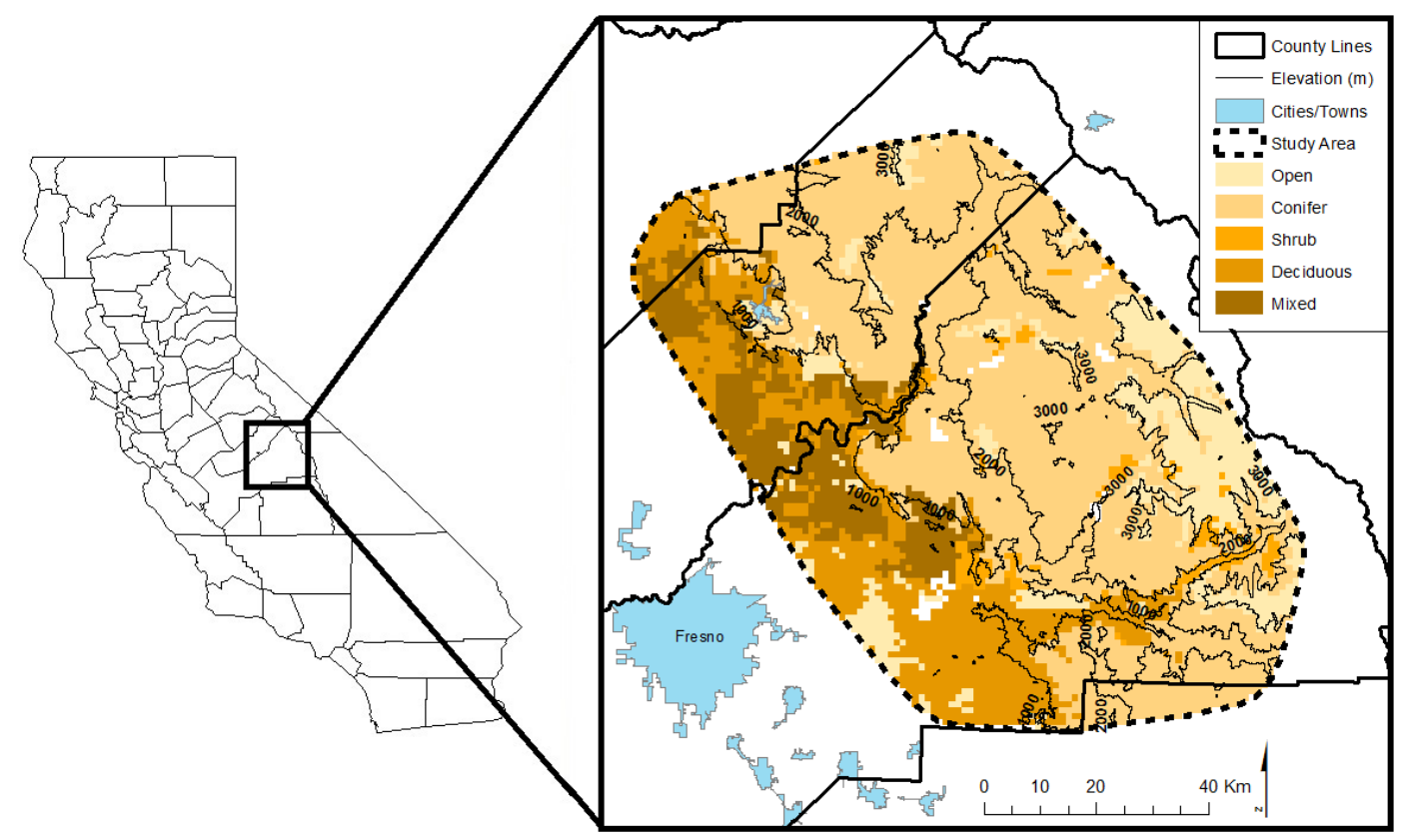

Fig. 1. Location of the study area in the Sierra National Forest from 1983 to 1992 . The study area is outlined by the dotted black line within the greater context of the Sierra Nevada and California.

Major habitat types changed with elevation and included, in order of increasing elevation, blue oak (Quercus douglasii) forest, black oak (Quercus kelloggii) forest, mountain alder (Alnus incana) forest, manzanita (Arctostaphylos spp.) chaparral, sagebrush (Artemisia spp.) scrub, ponderosa pine (Pinus ponderosa) forest, white fir (Abies concolor) forest, lodgepole pine (Pinus contorta) forest, and whitebark pine (Pinus albicaulis) forest (Sawyer et al. 2009). Mule deer were the most common large ungulate in the area. Other ungulates included feral wild pigs (Sus scrofa) and domestic cattle (Bos taurus). Co-occurring carnivore species in the area included American black bear (Ursus americanus), coyote (Canis latrans), gray fox (Urocyon cinereoargenteus), red fox (Vulpes vulpes), fisher (Pekania pennanti), and pine marten (Martes americana) (Neal et al. 1987).

\section{Field Methods}

Mountain lions were captured from 14 August 1983 to 28 March 1990. All animals were captured by using specially trained hounds between February and August in the Shaver Lake, Dinkey Creek, and North Fork Kings River areas of the Sierra National Forest. Capture efforts primarily coincided with summer and winter ranges of migratory deer. Once treed, mountain lions were immobilized with Telazol ${ }^{\circledR}$ (tiletamine $\mathrm{HCl}$ and zolazepam $\mathrm{HCl}$; Fort Dodge Animal Health, Fort Dodge, IA) delivered by a dart gun. Immobilized animals were sexed, aged, weighed, described, and outfitted with a VHF radio collar (MOD500, Telonics, Inc., Mesa, AZ). We followed methods of Shaw (1983) for aging animals. Some radio-collared mountain lions were recaptured using the above methods to replace worn radio collars. During and following the 1985 capture phase of the study, all mountain lion sign (e.g., tracks, scat) was recorded and mapped and compared with known locations of radio-collared individuals. Sightings, differences in track size, tracks associated with scrapes, and the presence of kitten tracks with adult tracks were used by experienced personnel to determine sex and age of uncollared mountain lions and possible relationships to collared individuals (Beausoleil et al. 2016). These data helped derive an annual minimum number of unmarked animals in the population (McBride et al. 2008). In some instances, known unmarked animals subsequently were radio-collared. Annual minimum number of unmarked animals averaged 3 (range 1-6) and 


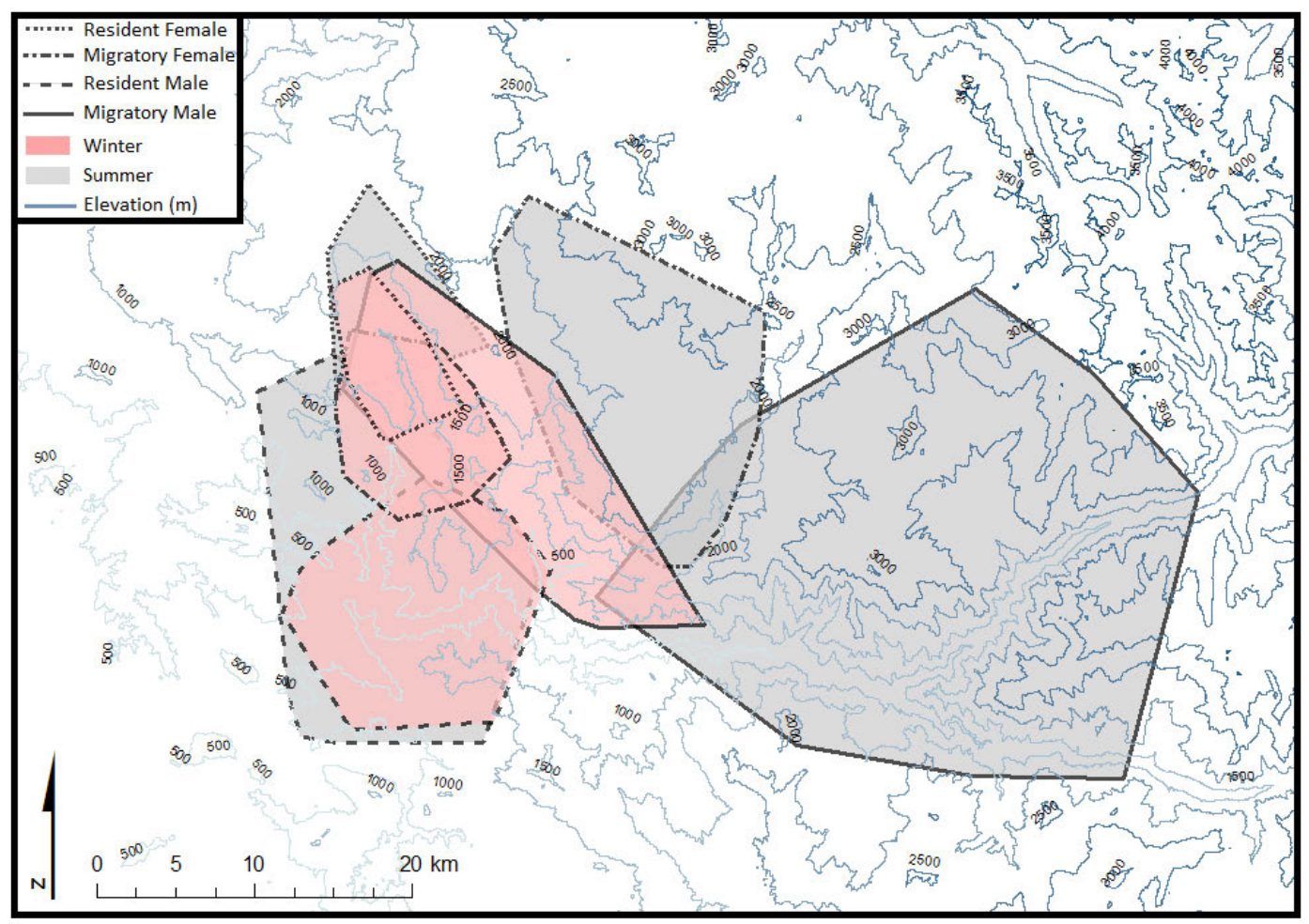

Fig. 2. Demonstration of seasonal shifts in $95 \%$ home range size as well as differences in seasonal elevational distribution for $95 \%$ home ranges of migratory animals relative to resident animals.

never exceeded the number of radio-collared animals.

Attempts were made to locate each radiocollared mountain lion several times per week. Field crews monitored and located telemetered mountain lions by triangulation on the ground, utilizing the extensive road network in the study area and conducting weekly fixedwinged aircraft flights. The flights were especially helpful in acquiring telemetry locations when lions were in areas where ground access would have been inefficient. An effort was made to estimate the size of error polygons for triangulations acquired using fixed-winged aircraft and ground telemetry, respectively. Error polygons were used in estimating home range size and standard error for each season within each year for each individual (Carrel et al. 1997, Land et al. 2008). Locations were plotted on hard-copy maps and entered into a computer database as Universal Transverse Mercator (UTM) coordinates.

Program R version 3.1.2 (R Core Team 2014) was used for statistical analyses. Additionally,
ArcView GIS version 10.2 (Esri, Redlands, CA) and Geospatial Modeling Environment version 0.7.4.0 (Beyer 2015) were used for spatial analyses. In all analyses, we considered $P \leq 0.05$ to be statistically significant and used a threshold of $r_{\mathrm{s}}=0.50$ for screening correlation between variables. No variables used met the above correlation threshold. Only adult mountain lions (estimated at $>24$ months of age) were included in data analysis unless otherwise noted. Animals radio-collared as subadults (estimated at 8-24 months of age) were not included in data analysis until they surpassed the minimum age threshold for adults and their movement patterns indicated establishment of a home range (Dellinger et al. 2013). We restricted analysis to adults, because they have established home ranges.

\section{Analysis of Spatial Data}

We performed single-factor ANOVAs using elevation (USGS 2015) of VHF triangulations averaged by month combined across years (Figs. 2, 3) and a binary classification of season 


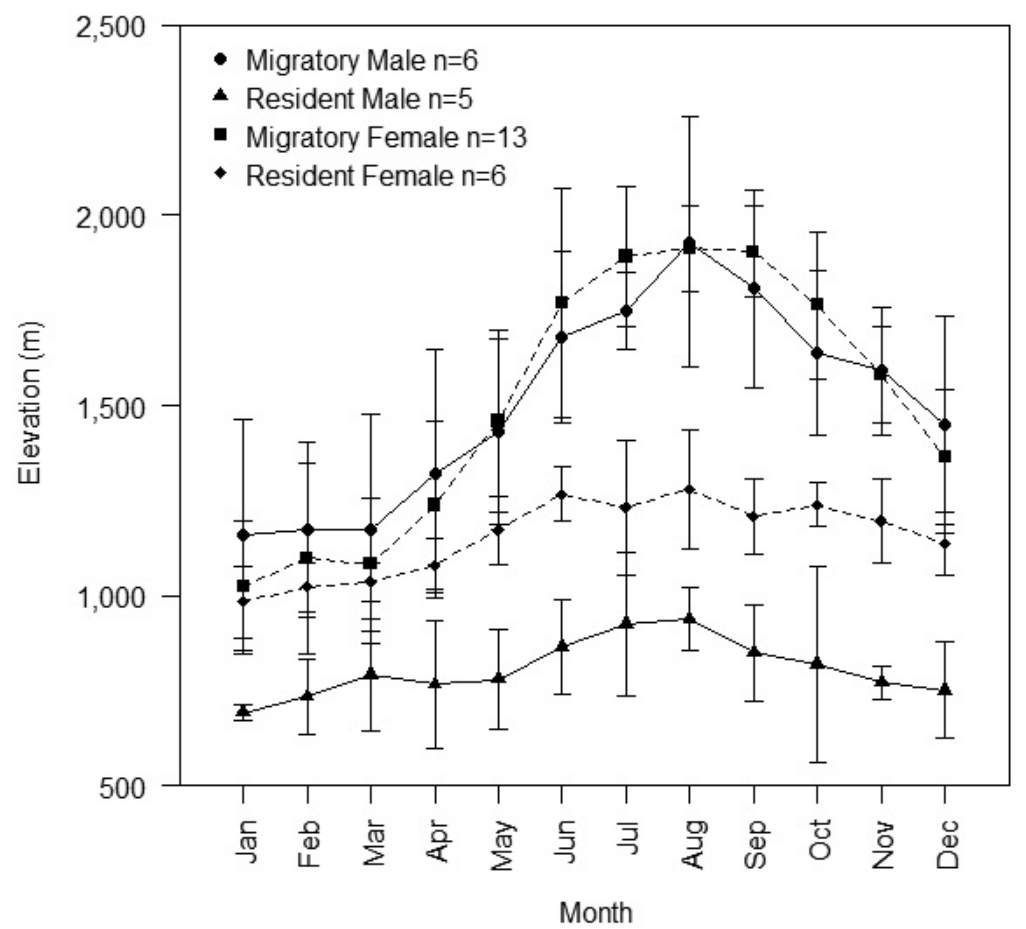

Fig. 3. Average elevation use of mountain lions (Puma concolor) by month and grouped by sex and migratory behavior in the Sierra Nevada from 1983 to 1992. Error bars are displayed for each month and group, respectively.

for each radio-collared mountain lion to test whether or not an individual exhibited migratory or resident behaviors on a seasonal basis. Winter included mid-November to mid-April, while summer included all other time periods. We screened the first 2 weeks of April and the last 2 weeks of November from these analyses to account for transition time between summer and winter locations, if in fact individuals did exhibit transitions. We deemed an individual migratory if an ANOVA demonstrated a significant difference between elevational distribution by month between seasons. We deemed an individual resident if an ANOVA demonstrated a nonsignificant difference between elevational distribution by month combined across years between seasons. Following this preliminary screening to determine whether individuals were resident or migratory, we performed linear regression using average elevation of seasonal home ranges of individuals for each year to determine which variables influenced elevational distribution of individuals. We acknowledge that this approach involved coarse-scale data analysis (monthly averages combined across years) and that individuals were classified as resident or migratory based on one statistical test. However, the nature of data acquisition via VHF triangulation precluded finer-scale analyses for classifying migratory behavior.

We regressed scaled values of elevation for individual VHF triangulations against migratory behavior $(0=$ resident, $1=$ migratory $)$, sex, season, and interactions between these 3 variables. We used stepwise selection to determine the best linear regression to explain elevational distribution of individuals. Nonsignificant terms were removed from the global model. We then compared the resulting model to the global model using a sum-of-squares $F$ test. If the resulting model was not significantly different from the global model, we considered it superior to the global model. We repeated this process until all terms were significant or until a more complex model was significantly different from a simpler resulting model. This method of determining the most parsimonious models performs well when few possible model subsets exist (Murtaugh 2009). 
We estimated $95 \%$ seasonal minimum convex polygons (MCPs) for each radio-collared animal, using $\mathrm{VHF}$ triangulations and the seasonal breakdown described above, to estimate overall home range size. For animals collared across multiple summer and/or winter seasons, individual 95\% seasonal MCPs were created for each season within each year. We set a minimum threshold of $30 \mathrm{VHF}$ triangulations per season for each year for individual $95 \%$ seasonal MCPs (Girard et al. 2002). The area $\left(\mathrm{km}^{2}\right)$ of all individual seasonal MCPs by year was normalized using a natural log transformation.

A linear regression was then developed where the transformed area values were regressed against migratory behavior, sex, season, and interactions between these 3 variables to determine which set of variables and potential interactions best explained the variance in overall home range size. Stepwise selection was again used to determine the most parsimonious linear regression for overall home range size (Murtaugh 2009).

Spatial overlap of $95 \%$ seasonal MCPs was calculated for all possible pairwise combinations ( $N=486$ combinations) of any 2 adult lions present during a season (Fieberg and Kochanny 2005). Animals with nonoverlapping seasonal home ranges were not included in this analysis. Analyses are presented for all possible interaction types: female overlap (F:F), male overlap (M:M), and male and female overlap (M:F). The formula for calculating home range overlap was

$$
\text { Sqrt of }([\mathrm{AB} / \mathrm{A}] *[\mathrm{AB} / \mathrm{B}]) \text {, }
$$

where $\mathrm{AB}=$ area occupied by both animal $\mathrm{A}$ and $\mathrm{B} ; \mathrm{A}=$ home range of animal $\mathrm{A}$; and $\mathrm{B}=$ home range of animal B (Fieberg and Kochanny 2005). The resulting overlap was normalized using an arcsine square root transformation.

Using a linear regression, we then examined whether there was a significant difference in overlap among the 3 interaction types and whether overlap varied significantly between seasons for each interaction type. Stepwise selection was used to determine the most parsimonious linear regression for home range overlap (Murtaugh 2009).

\section{Density Estimation}

We calculated a minimum population density (animals/100 $\mathrm{km}^{2}$ ) for collared mountain lions and unmarked mountain lions (identified from tracks and compared to known locations of radio-collared animals) present in the core study area from winter 1984 to winter 1991 by year and season, following methods outlined in Cooley et al. (2009) and Elbroch and Wittmer (2012). We combined the location data for all females that remained in the core study area (i.e., where we repeatedly surveyed for mountain lions and where the majority of capture efforts took place) for a given year and season. A single 95\% MCP was created from this combined location data. Next, we determined the proportion that each additional overlapping mountain lion home range overlapped with the combined MCP. These additional animals included all radio-collared males and females and those unmarked animals whose home ranges fell outside of the core study area to some degree. Then we summed the proportion of overlap for each additional animal with the combined MCP of females in the core study area (Cooley et al. 2009, Elbroch and Wittmer 2012). This yielded a minimum density based on all known adult mountain lions in the core study area. After we did this for each year and season, we conducted a $t$ test to determine whether minimum mountain lion density varied between seasons. We acknowledge that our results are based on a minimum density estimate, as we potentially did not account for all unmarked animals in the study area. Further, exclusion of animals $\leq 24$ months old from density estimation makes it obvious that our estimates underreport the overall density of mountain lions. However, adult density estimation (animals > 24 months) is in line with previous work and allows for better comparison of estimates between studies (Cougar Management Guidelines Working Group 2005).

\section{REsults}

Over the course of the study, 30 mountain lions (19 females and 11 males) were fitted with VHF radio collars. Nine of these animals (7 females and 2 male) were initially collared as subadults (estimated at 8-24 months old) and subsequently surpassed the minimum age threshold (>24 months; Cooley et al. 2009, Elbroch and Wittmer 2012) to be considered an adult while being radio-collared. Of the 9 radio-collared subadults, only 5 (4 females 


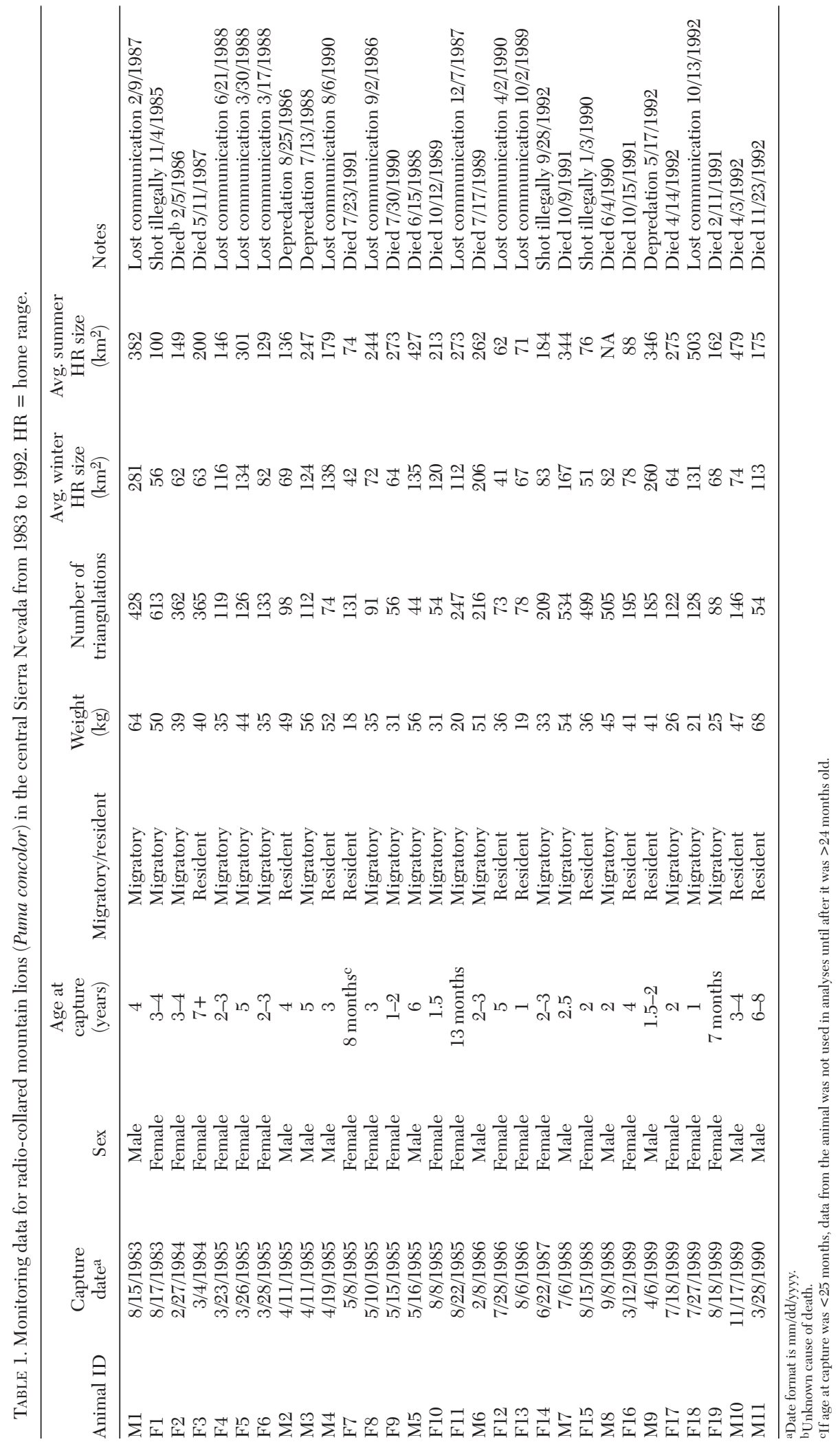


TABLE 2. Average seasonal home range size $\left(\mathrm{km}^{2}\right)$ of radio-collared mountain lions (Puma concolor) in the central Sierra Nevada from 1983 to 1992 . Home range sizes are averaged by migratory behavior, season, and sex. Standard errors are in parentheses.

\begin{tabular}{lcclcc}
\hline & \multicolumn{2}{c}{ Resident } & & \multicolumn{2}{c}{ Migratory } \\
\cline { 2 - 3 } \cline { 6 - 6 } & Summer & Winter & & Summer & Winter \\
\hline Male & $249(48.9)$ & $121(19.9)$ & & $340(28.2)$ & $219(46.0)$ \\
Female & $131(38.7)$ & $56(9.1)$ & & $228(31.1)$ & $91(8.3)$ \\
\hline
\end{tabular}

TABLE 3. Coefficient estimates for the most parsimonious linear regression explaining variance in elevational distribution of radio-collared mountain lions (Puma concolor) in the central Sierra Nevada from 1983 to 1992.

\begin{tabular}{lcc}
\hline Coefficient & Estimate & SE \\
\hline Intercept & 0.93 & 0.013 \\
Migratory & 0.28 & 0.015 \\
Sex & -0.33 & 0.019 \\
Season & -0.09 & 0.017 \\
Migratory $\times$ sex & 0.40 & 0.019 \\
Migratory $\times$ season & -0.31 & 0.018 \\
Sex $\times$ season & 0.04 & 0.018 \\
\hline
\end{tabular}

and 1 male) were able to be determined as offspring of a specific radio-collared adult female. There were 6085 total VHF triangulations for all animals combined over the entire study $(\bar{x}=203$, range 44-613; Table 1). Triangulation error averaged $151 \mathrm{~m}(\mathrm{SE}=19)$ for aerial locations and $42 \mathrm{~m}(\mathrm{SE}=15)$ for ground locations. Average home range size by sex, season, and migratory behavior are presented in Table 2 .

\section{Spatial Analyses}

Single factor ANOVAs revealed that 6 and 5 adult males exhibited migratory and resident behavior, respectively. Further, 13 and 6 adult females exhibited migratory and resident behavior, respectively (Figs. 2, 3). Upon reaching adulthood, all but one of the 5 animals radio-collared as subadults with known maternity exhibited the same behavior as the radiocollared mother. Stepwise model selection using seasonal home ranges of individuals in each year revealed that the most parsimonious linear regression for determining which variables influenced elevational distribution of individuals included migratory behavior, sex, season, and all pairwise interactions of these 3 variables (Table 3). The next best model included all 3 individual variables and all pairwise interactions except a season-by-sex interaction. An $F$ test comparing these 2 models indicated that the more complex model was the most parsimonious $\left(F_{7,8}=5.32, P=0.02\right)$. Odds ratios (allowing for 1:1 comparisons) derived from the coefficient estimates of the most parsimonious model demonstrate the variation in elevations occupied by different classes of individuals (according to sex and migratory behavior) between seasons (Fig. 4). According to odds ratios, migratory males in summer occupied the highest elevations, followed by migratory females in summer. Resident males occupied the lowest elevations regardless of season.

The most parsimonious linear regression for determining which variables best explained variation in overall home range size included only 3 individual variables: migratory behavior, sex, and season (Table 4). No interaction terms were included in the most parsimonious model. The next best model included all 3 individual variables and an interaction between season and sex. An $F$ test indicated that the simpler model was the most parsimonious $\left(F_{5,6}=0.44, P=0.51\right)$. Odds ratios derived from the coefficient estimates of the most parsimonious model demonstrate the average overall home range sizes of different classes of individuals between seasons (Fig. 5). In general, home range size in winter was approximately half the home range size in summer for all classes of individuals (Fig. 2).

In general, M:M home range overlap was less than $\mathrm{F}: \mathrm{F}$ and $\mathrm{M}: \mathrm{F}$ home range overlap (Table 5). Overlap for M:M was greater in summer than in winter. The most parsimonious linear regression for determining which variables best explained variation in home range overlap included only $\mathrm{M}: \mathrm{M}$ (intercept $=$ 0.55 with $\mathrm{SE}=0.014$; coefficient estimate $=$ -0.09 with $\mathrm{SE}=0.045)$. This indicates that M:M home range overlap was significantly less than the other interaction types. Further, this indicates that there was no significant difference between F:F and M:F home range overlap; nor was there a seasonal effect indicating that amount of home range overlap changed significantly between seasons for any interaction type. The next best model included a seasonal effect and an interaction between M:M overlap and season. An $F$ test comparing these 2 models indicated that the simpler model was the most parsimonious $\left(F_{3,5}=\right.$ $1.23, P=0.29$ ). Odds ratios derived from the coefficient estimates of the most parsimonious 


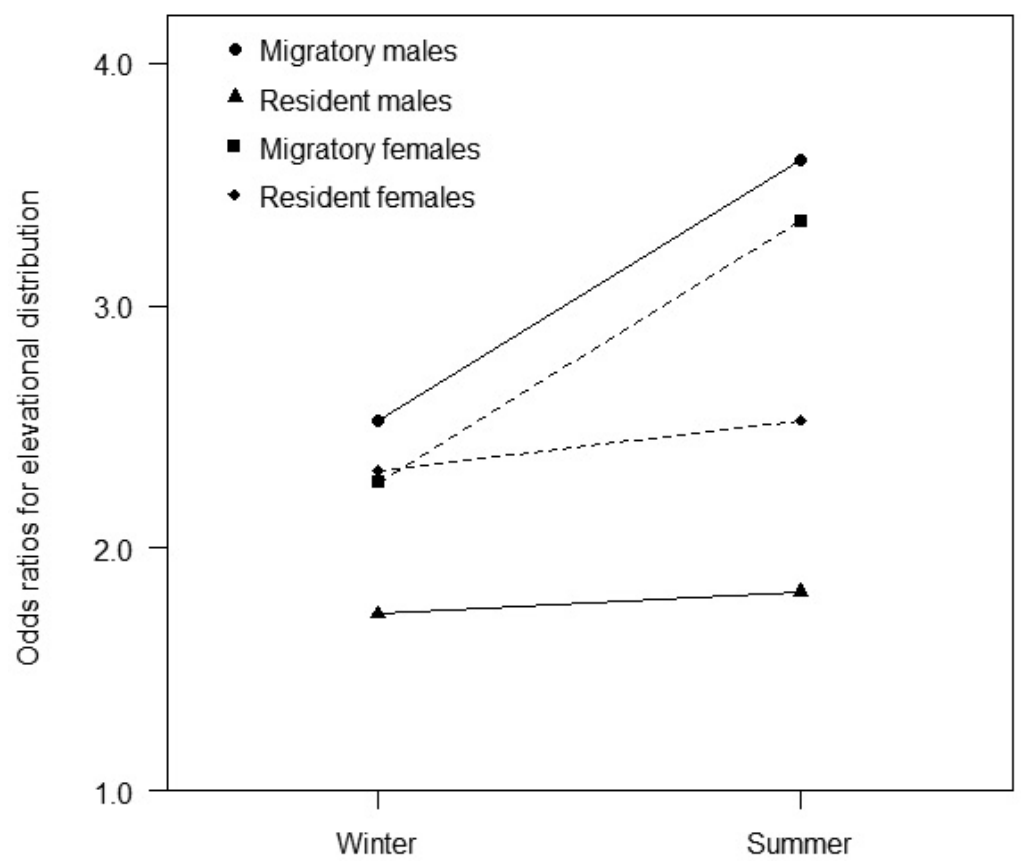

Fig. 4. Odds ratios for seasonal elevational distribution $(\mathrm{m})$ of mountain lions (Puma concolor), grouped by sex and migratory behavior, in the Sierra Nevada from 1983 to 1992.

TABLe 4. Coefficient estimates for the most parsimonious linear regression explaining variance in home range size $\left(\mathrm{km}^{2}\right)$ of mountain lions (Puma concolor) in the southern Sierra Nevada from 1983 to 1992.

\begin{tabular}{lcc}
\hline Coefficient & Estimate & SE \\
\hline Intercept & 3.82 & 0.111 \\
Season & 0.75 & 0.105 \\
Sex & 0.77 & 0.113 \\
Migratory & 0.54 & 0.111 \\
\hline
\end{tabular}

model demonstrate that F:F and M:F home ranges overlapped 1.35 times more than $\mathrm{M}: \mathrm{M}$ home ranges, with respect to overall home range size of each individual involved.

\section{Density Estimation}

Minimum density of all collared and unmarked mountain lions was 1.42 per $100 \mathrm{~km}^{2}$ in winter and 0.87 per $100 \mathrm{~km}^{2}$ in summer (Fig. 6). Minimum densities of collared and unmarked adult females and males in winter were 1.11 and 0.31 per $100 \mathrm{~km}^{2}$, respectively, and in summer were 0.65 and 0.22 per $100 \mathrm{~km}^{2}$, respectively. According to a $t$ test, density of minimum known mountain lions was significantly greater in winter compared to summer $\left(t_{12}=-2.47, P=0.03\right)$.

\section{Discussion}

We set out to test various hypotheses related to seasonal spatial ecology of mountain lions in the central Sierra Nevada using a historic data set collected over 10 years. Given that the majority of the mule deer in the study area were migratory rather than resident (Longhurst et al. 1952, Bertram and Rempel 1977, Neal et al. 1987, Higley 2002), our hypotheses were based on the idea that mountain lion spatial ecology would reflect spatial ecology of the more abundant migratory mule deer in the study area. All of our original hypotheses were supported by our data analyses, with the exception of a hypothesized increase in home range overlap in winter compared to summer. Further, we conclude that, like the mule deer, not all mountain lions in the study area were migratory (Fig. 3; Pierce et al. 1999), demonstrating contrasting behavioral strategies between individual carnivores within a population attempting to meet metabolic demands. Previous research has demonstrated a similar dichotomy in seasonal behavior of gray wolves (Canis lupus) in relation to barren ground caribou (Rangifer tarandus; Musiani et al. 2007), elk (Cervus 


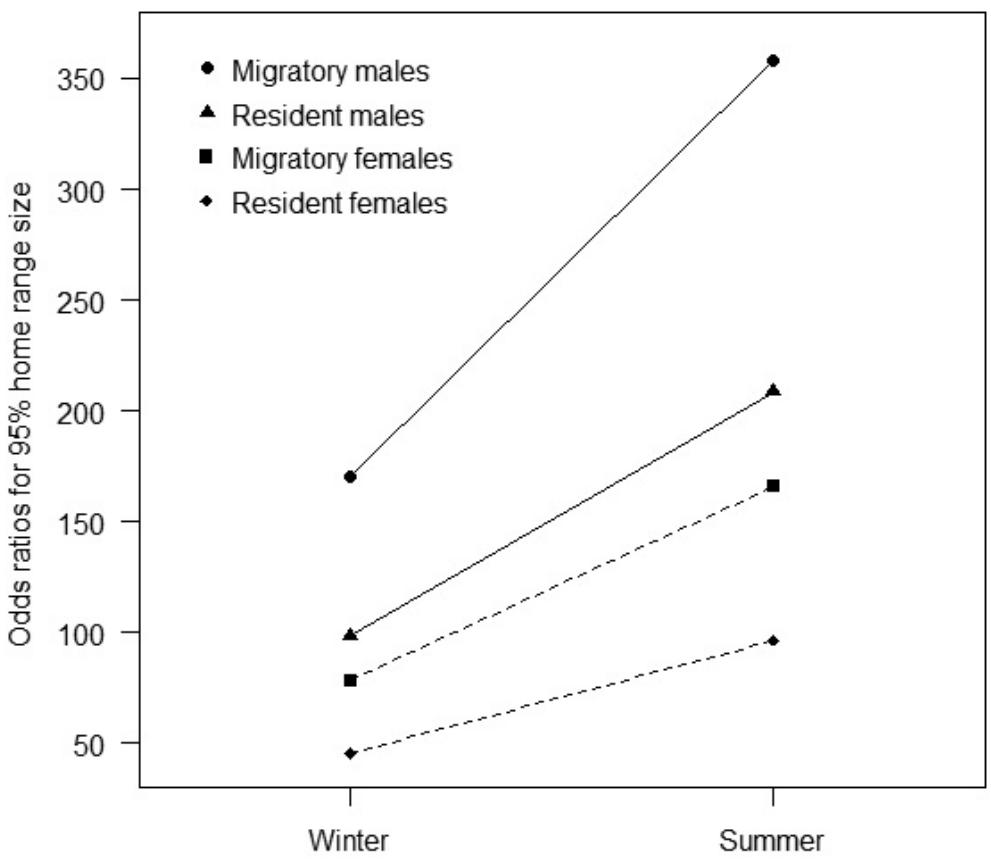

Fig. 5. Odds ratios for seasonal home range size $\left(\mathrm{km}^{2}\right)$ of mountain lions (Puma concolor), grouped by sex and migratory behavior, in the Sierra Nevada from 1983 to 1992.

TABLE 5. Percent home range overlap of mountain lions (Puma concolor) in the southern Sierra Nevada from 1983 to 1992, averaged by interaction type and season.

\begin{tabular}{lcc}
\hline Interaction by season & Overlap & SD \\
\hline Male: male summer & 0.27 & 0.19 \\
Male: male winter & 0.16 & 0.10 \\
Male:female summer & 0.31 & 0.22 \\
Male:female winter & 0.29 & 0.21 \\
Female:female summer & 0.28 & 0.23 \\
Female:female winter & 0.33 & 0.24 \\
\hline
\end{tabular}

elaphus; Nelson et al. 2012), and white-tailed deer (Odocoileus virginianus; Forbes and Theberge 1996). Such findings have import for management and conservation of mountain lions and other large carnivores.

Previous research on deer in our study area demonstrated that migratory mule deer spent the summer at around $2000-3000 \mathrm{~m}$ in elevation (Bertram and Rempel 1977, Chapel and Rempel 1981). Further, in late November deer migrated to winter ranges $<1200 \mathrm{~m}$ in elevation. Such movements may explain the migratory behavior and seasonal spatial patterns (Figs. 3, 4) exhibited by some, but not all, of the mountain lions in this study. Given the limited geographic extent of deer winter range relative to summer range, deer densities on winter ranges in our study area were known to greatly exceeded those on summer ranges (Bertram and Rempel 1977, Bertram 1984). Increasing deer densities on small winter ranges may explain increasing mountain lion densities (Fig. 6) and decreasing mountain lion home range size at lower elevations (Fig. 5) during winter. Mountain lion home range overlap did not increase in winter (Table 5) with increasing mountain lion density, but this could have been mediated by significant decreases in mountain lion home range size, presumably due to decreased deer home range extent and increased availability of deer on winter range during the same time period.

Migratory deer movements do not explain all mountain lion spatial patterns in this study. Resident mountain lions spent the summer at lower elevations than the summer ranges of migratory deer herds (Fig. 3). Given the low abundance of resident versus migratory deer, resident mountain lions must have utilized various secondary prey items (e.g., wild pigs, livestock, pets, and small rodents; Neal et al. 1987) during summer to balance nutritional demands (Torres et al. 1996, Pierce et al. 2000).

Reports of pet and livestock losses generally increased in our study area after migratory 


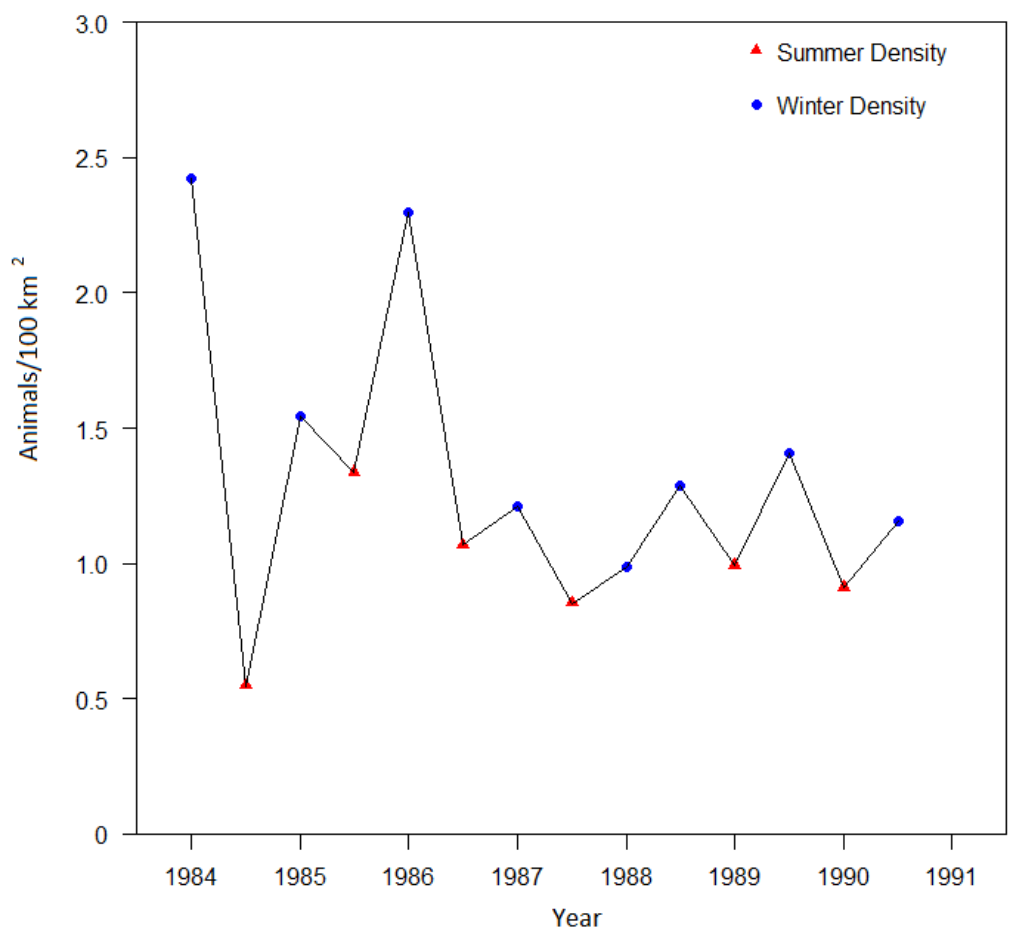

Fig. 6. Seasonal density (individuals per $100 \mathrm{~km}^{2}$ ) of mountain lions (Puma concolor) in the Sierra Nevada from 1983 to 1992 .

mule deer traveled to higher elevations in spring and early summer (Neal et al. 1987). Similar trends have been found throughout California (Rudd 2017). Linking study animals to reported losses was difficult, given the irregular occurrence of successful VHF triangulations of kill clusters, but it is likely that there is a relationship between increased livestock losses and resident mountain lion spatial patterns in summer at lower elevations (Torres et al. 1996). During summer, resident mountain lions frequently occurred on cattle ranches or rural ranchette developments. This observation is corroborated by the fact that 3 resident study animals were taken on depredation permits. Future research should examine trends in temporal occurrence of mountain lion depredations on pets and livestock in the area and relationship to migratory strategy and seasonal foraging ecology of mountain lions in the area. Such depredation patterns may be predicted in areas with migratory deer herds. This insight might inform management of mountain lion-livestock conflict situations by allowing recommendations for changes in husbandry practices of domestic animals in certain areas at certain times of the year (Nelson et al. 2012).

Understanding the contrasting behavioral strategies of resident and migratory mountain lions could provide insight into various aspects of individual fitness and overall population trends through time. For example, at the individual level these contrasting behavioral strategies could explain why some females are more fecund than others. Though data from this study is limited, all known recruited offspring belonged to migratory females, despite the fact that both resident and migratory females produced kittens during the study. Migratory females have year-round access to migratory deer, whereas resident females likely have to subsist on secondary prey items to a larger degree during summer, which might not regularly meet metabolic demands of a female and her kittens (Pierce et al. 1999, Cooley et al. 2009). From a population perspective, research has recently demonstrated divergent prey selection, habitat use, seasonal movement, and even gene flow patterns between neighboring large carnivores with different behavioral strategies (migratory vs. 
resident; Musiani et al. 2007). Thus, behavioral strategies exhibited by individuals are as important as demographic parameters in explaining variability in a suite of ecological parameters (e.g., habitat use, survivorship, gene flow, and population size; Grigione et al. 2002).

Despite differences in behavioral strategies among mountain lions, wildlife managers and researchers should be compelled to effectively manage and conserve mountain lion populations such that these differing behavioral strategies persist within a population. This is especially true given that variability in behavioral strategies increases the robustness of a population to withstand perturbations (Carmichael et al. 2001, Ernest et al. 2003, Musiani et al. 2007, Ernest et al. 2014). Human encroachment on habitat and changing climate patterns represent environmental stochasticity to which mountain lions must adjust (Burdett et al. 2010, Jennings et al. 2016). Fostering migratory mountain lion behavior likely requires identifying and conserving migration corridors, as well as summer and winter ranges of mule deer (Carmichael et al. 2001, Morrison and Boyce 2009). Maintaining resident mountain lion behavior requires employing necessary animal husbandry practices in low-elevation habitats (Torres et al. 1996). We acknowledge that mountain lions exhibit a far more diverse suite of behavioral strategies than mentioned herein (Hansen 1992, Logan and Sweanor 2001, Hornocker and Negri 2010). However, even the simplistic dichotomy highlighted herein informs mountain lion conservation and management. Therefore, given the high likelihood that mountain lions display a diverse suite of behavioral strategies throughout their geographic range (Dickson and Beier 2002, Cox et al. 2006, Elbroch and Wittmer 2012), insight into mountain lion spatial patterns in different ecoregions is key to maintaining and promoting behavioral variability and populations therein.

\section{ACKNOWLEDGMENTS}

This work was supported by the Pacific Southwest Forest and Range Experimental Station, the California Department of Fish and Game, the Fresno County Recreation and Wildlife Commission, and the Sierra National Forest. We thank G. Steger, B. Fazio, C. Evans, J. Oldham, G. Eberlein, S. Willems, and others for collection and processing of field data. Pilots B. Cole and L. Goering flew several hundred flights to monitor collared animals. D. Fjelline, C. Wiley, R. Nelson, B. Milsap, and G. Fluornoy captured the mountain lions with their dogs. R. Rempel, Doug B., J. Markel, and M. Boland assisted with capture operations and tranquilized, collared, and gathered data on all lions in the project.

\section{Literature Cited}

Beausoleil, R.A., J.D. Clark, and B.T. Maletzke. 2016. A long-term evaluation of biopsy darts and DNA to estimate cougar density. Wildlife Society Bulletin 40:583-592.

BeIER, P. 1993. Determining minimum habitat areas and habitat corridors for cougars. Conservation Biology 7:94-108.

Bertram, R. 1984. The North Kings deer herd study. California Department of Fish and Game Report, Sacramento, CA. 222 pp.

Bertram, R., and R. Rempel. 1977. Migration of the North Kings deer herd. California Fish and Game 63:157-179

Beyer, H.L. 2015. Geospatial Modelling Environment, Version 0.7.4.0. http://www.spatialecology.com/gme

Burdett, C.L., K.R. Crooks, D.M. Theobald, K.R. WilSON, E.E. Boydston, L.M. LyREN, R.N. Fisher, T.W. Vickers, S.A. Morrison, AND W.M. Boyce. 2010. Interfacing models of wildlife habitat and human development to predict the future distribution of puma habitat. Ecosphere 1:1-21.

Carmichael, L.E., J.A. Nagy, N.C. Larter, and C. STRoвECK. 2001. Prey specialization may influence patterns of gene flow in wolves of the Canadian Northwest. Molecular Ecology 10:2787-2798.

Carrel, W.K., R.A. Ockenfels, J.A. Wennerlund, and J.C. DeVos JR. 1997. Topographic mapping, Loran-C, and GPS accuracy for aerial telemetry locations. Journal of Wildlife Management 61:1406-1412.

Chapel, M., and R. Rempel. 1981. Management plan for the North Kings deer herd. United States Forest Service. $81 \mathrm{pp}$.

Cooley, H.S., R.B. Wielgus, G. Koehler, and B. MALETZKe. 2009. Source populations in carnivore management: cougar demography and emigration in a lightly hunted population. Animal Conservation 12:321-328.

Cougar Management Guidelines Working Group. 2005. Cougar management guidelines. WildFutures, Bainbridge Island, WA.

Cox, J.J., D.S. MaEhr, and J.L. LARKIn. 2006. Florida panther habitat use: new approach to an old problem. Journal of Wildlife Management 70:1778-1785.

Currier, M.J.P. 1983. Felis concolor. Mammalian Species 200:1-7.

Dellinger, J.A., C. Proctor, T.D. Steury, M.J. Kelly, and M.R. Vaughan. 2013. Habitat selection of a large carnivore, the red wolf, in a human-altered landscape. Biological Conservation 157:324-330.

Dickson, B.G., AND P. BEIER. 2002. Home-range and habitat selection by adult cougars in southern California. Journal of Wildlife Management 66:1235-1245. 
Elbroch, L.M., And H.U. Wittmer. 2012. Puma spatial ecology in open habitats with aggregate prey. Mammalian Biology 77:377-384.

Ernest, H.B., W.M. Boyce, V.C. Bleich, B. May, S.J. Stiver, AND S.G. ToRRES. 2003. Genetic structure of mountain lion (Puma concolor) populations in California. Conservation Genetics 4:353-366.

Ernest, H.B., T.W. Vickers, S.A. Morrison, M.R. BUCHALSKI, AND W.M. BOYCE. 2014. Fractured genetic connectivity threatens a southern California puma (Puma concolor) population. PLOS ONE 9: e107985.

Fieberg, J., ANd C.O. Kochanny. 2005. Quantifying homerange overlap: the importance of the utilization distribution. Journal of Wildlife Management 69: 1346-1359.

Forbes, G.J., And J.B. Theberge. 1996. Response by wolves to prey variation in central Ontario. Canadian Journal of Zoology 74:1511-1520.

Girard, I., J.P. Ouellet, R. Courtois, C. Dussault, and L. BRETON. 2002. Effects of sampling effort based on GPS telemetry on home-range size estimations. Journal of Wildlife Management 66:1290-1300.

Grigione, M.M., P. Beier, R.A. Hopkins, D. Neal, W.D. Padley, C.M. SChONEWALd, and M.L. Johnson. 2002. Ecological and allometric determinants of home range size for mountain lions (Puma concolor). Animal Conservation 5:317-324.

Hansen, K. 1992. Cougar, the American lion. Northland Publishing, Flagstaff, AZ.

Hayes, C.L., E.S. Rubin, M.C. Jorgensen, R.A. Botta, AND W.M. BoyCE. 2000. Mountain lion predation of bighorn sheep in the Peninsular Ranges, California. Journal of Wildlife Management 64:954-959.

Higley, J.M. 2002. Hunting deer in California. Deer Herd Management Plan Implementation Program, Sacramento, CA. 87 pp. https://nrm.dfg.ca.gov/File Handler.ashx? DocumentID $=23228$

Hornocker, M., AND S. Negri, EDITORs. 2010. Cougar: ecology and conservation. University of Chicago Press, Chicago, IL.

Jennings, M.K., R.L. Lewison, T.W. Vickers, and W.M. BOYCE. 2016. Puma response to the effects of fire and urbanization. Journal of Wildlife Management 80:221-234

Kelly, M.J., A.J. Noss, M.S. Di Bitetti, L. Maffei, R.L. Arispe, A. Paviolo, C.D. De Angelo, and Y.E. Di BLANCO. 2008. Estimating puma densities from camera trapping across three study sites: Bolivia, Argentina, and Belize. Journal of Mammalogy 89: 408-418.

Land, E.D., D.B. Shindle, R.J. Kawula, J.F. Benson, M.A. LotZ, AND D.P. ORonato. 2008. Florida panther habitat selection analysis of concurrent GPS and VHF telemetry data. Journal of Wildlife Management 72:633-639.

Logan, K., And L. Sweanor. 2001. Desert puma: evolutionary ecology and conservation of an enduring carnivore. Island Press, Covelo, CA.

Longhurst, W.M., A.S. LeOpold, and R.F. Dasman. 1952. A survey of California deer herds: their ranges and management problems. California Fish and Game Bulletin 6:1-136.

McBride, R.T., R.T. McBride, R.M. McBride, and C.E. MCBride. 2008. Counting pumas by categorizing physical evidence. Southeastern Naturalist 7: $381-400$
Morrison, S.A., And W.M. Boyce. 2009. Conserving connectivity: some lessons from mountain lions in southern California. Conservation Biology 23: 275-285.

Murtaugh, P.A. 2009. Performance of several variable selection methods applied to real ecological data. Ecology Letters 12:1061-1068.

Musiani, M., J.A. Leonard, H. Cluff, C.C. Gates, S. Mariani, P.C. Paquet, C. Vilà, and R.K. Wayne. 2007. Differentiation of tundra/taiga and boreal coniferous forest wolves: genetics, coat colour and association with migratory caribou. Molecular Ecology 16:4149-4170.

Neal, D.L., G.N. Stegar, and R.C. Bertram. 1987. Mountain lions: preliminary findings on home-range use and density in the central Sierra Nevada. Pacific Southwest Forest and Range Experimental Station, Research Note PSW-392.

Nelson, A.A., M.J. Kauffman, A.D. Middleton, M.D. Jimenez, D.E. MCWhirter, J. Barber, AND K. GEROW. 2012. Elk migration patterns and human activity influence wolf habitat use in the Greater Yellowstone Ecosystem. Ecological Applications 22: 2293-2307.

OrLando, A.M. 2008. Impacts of rural development on puma ecology in California's Sierra Nevada. Doctoral dissertation, University of California-Davis, Davis, CA.

Pierce, B.M., V.C. Bleich, and R.T. Bowyer. 2000. Selection of mule deer by mountain lions and coyotes: effects of hunting style, body size, and reproductive status. Journal of Mammalogy 81:462-472.

Pierce, B.M., V.C. Bleich, J.D. Wehausen, and R.T. BOWYER. 1999. Migratory patterns of mountain lions: implications for social regulation and conservation. Journal of Mammalogy 80:986-992.

R Core Team. 2014. R: a language and environment for statistical computing. R Foundation for Statistical Computing, Vienna, Austria. https://www.R-project .org/

RUDD, J. 2017. Findings of necropsies on mountain lions taken under depredation permits. California Department of Fish and Wildlife, Sacramento, CA. 4 pp.

Sawyer, J.O., T. Keehler-Wolf, And J.M. Evens. 2009. A manual of California vegetation. California Native Plant Society, Sacramento, CA.

Shaw, H.G. 1983. Mountain lion field guide. Arizona Game and Fish Department, Mesa, AZ. Special Report Number 9. 47 pp.

SMALLWOOD, K.S. 1997. Interpreting puma (Puma concolor) population estimates for theory and management. Environmental Conservation 24:283-289.

Thorne, J.H., D. Cameron, AND J.F. Quinn. 2006. A conservation design for the central coast of California and the evaluation of mountain lion as an umbrella species. Natural Areas Journal 26:137-148.

Torres, S.G., T.M. Mansfield, J.E. Foley, T. Lupo, and A. Brinkhaus. 1996. Mountain lion and human activity in California: testing speculations. Wildlife Society Bulletin 24:451-460.

[USGS] United States Geological Survey. 2015. National elevation database. [Accessed January 2016]. http://nationalmap.gov/elevation.html

Wehausen, J.D. 1996. Effects of mountain lion predation on bighorn sheep in the Sierra Nevada and Granite Mountains of California. Wildlife Society Bulletin 24:471-479. 
Wilmers, C.C., Y. Wang, B. Nickel, P. Houghtaling, Y. Shakeri, M.L. Allen, J. Kermish-Wells, V. YovoVICH, AND T. Williams. 2013. Scale dependent behavioral responses to human development by a large predator, the puma. PLOS ONE 8:e60590.

Winter, F.A., G. Ashcraft, and B. Stewart. 1970. North Kings deer herd management plan. United States Forest Service. $44 \mathrm{pp}$.

Received 25 July 2017

Revised 11 January 2018

Accepted 14 March 2018

Published online 12 July 2018 